\title{
Monitoring roots of grazed rangeland vegetation with the root periscope/mini-rhizotron technique
}

\section{MICHAEL G. KARL AND PAUL S. DOESCHER}

\begin{abstract}
The root periscope/mini-rhizotron technique has been used most commonly to monitor root growth of field crops in a nondestructive manner. This study introduces a successful application of the technique for monitoring root growth of grazed rangeland vegetation. The relative, root growth response of orchardgrass (Dactylis glomerata L. 'Potomac') to defoliation by cattle was monitored on a conifer plantation in southwest Oregon. Despite stocking densities of about 2.7-4.4 animal unit/ha and 19 days of grazing during 1988, trampling and breakage of mini-rhizotrons on the cattle-grazed area was minimal. Defoliation by cattle had a negative impact on the relative number of roots for grazed orchardgrass in June and July $(P<0.05)$. Cautions and limitations for the use of the technique on rangelands are presented. The root periscope/mini-rhizotron appears to be a suitable, nondestructive, and affordable (\$1,000-1,200 per root periscope; $\mathbf{9 8 . 5 0}$ per minirhizotron) technique for monitoring root growth of rangeland vegetation defoliated by livestock and/or native ungulates.
\end{abstract}

Key Words: cattle grazing, root growth, Dactylis glomerata, root periscope/mini-rhizotron

\footnotetext{
Authors are graduate research assistant and assistant professor, Department of Rangeland Resources, Oregon State University, Corvallis 97331.

Research was funded by the USDI Bureau of Land Management, Medford District, Medford, Oregon 97502. Authors wish to acknowledge Bob Schnekenburger, machine foreman, and E. Stuart Baker, senior research assistant, Department of Agricultural Engineering, Oregon State University, for modifications and construction of the root periscope. We thank R.H. Maier, scientific glassblower, for cutting the Pyrex glass. Special thanks to Peter Halvorson and Noraza Abu Bakar for their assistance in the field

Constructive reviews of this manuscript were provided by W.C. Krueger, S.H. Sharrow, and R.F. Miller.

This article is submitted as Technical Paper 8983, Oregon Agricultural Experiment Station, Corvallis.

For reprints, contact Paul S. Doescher, Department of Rangeland Resources, Oregon State University, Corvallis 97331-6704

Manuscript accepted 9 July 1990.
}

Use of a root periscope (Richards 1984) and mini-rhizotrons (Böhm 1979) has become an accepted method for investigating the behavior of roots in a nondestructive manner. The method arose from an investigation by Bates (1937), who first used a light source/mirror assembly to observe roots growing along the exterior surface of glass tubes. Since 1937 , the light source/mirror assembly has been variously modified and improved. The root periscope is but one of these modifications. The tubes have been made of glass (Bates 1937, Gregory 1979, Richards 1984, this study), or acrylic plastic (Waddington 1971, Sanders and Brown 1978, Upchurch and Ritchie 1983, Vos and Groenwold 1983), and have been named "mini-rhizotrons" (Böhm 1974, in Böhm 1979), when installed in natural soil profiles.

The root periscope/mini-rhizotron technique has been used most often in agronomic research. For example, Waddington (1971), probably the first since Bates (1937) to use the technique, observed root growth of spring wheat (Triticum aestivum L.). A more complete listing of agricultural crops which have been studied with this technique can be found in Brown and Upchurch (1987).

On rangeland, the root periscope/mini-rhizotron technique has only recently been applied. Richards (1984) pioneered its use in range management through his investigations of clipping and subsequent root response for 2 species of bunchgrass. To our knowledge, the root periscope/mini-rhizotron technique has not been used to investigate root responses of range vegetation subjected to grazing by livestock. We suspect that the potential for trampling and breakage of mini-rhizotrons by livestock has been a factor preventing the prior use of the technique on grazed rangelands.

The purpose of this paper is to provide evidence for the successful use of the root periscope/mini-rhizotron technique for moni- 
toring root growth on grazed rangelands.

\section{Materials and Methods}

\section{Root Periscope Design}

The root periscope used was a modification of the one shown in Figure 1 of Richards (1984). We used an aluminum tube of $112-\mathrm{cm}$ length, and $3.175-\mathrm{cm}$ diam, capable of monitoring root growth to a $75-\mathrm{cm}$ depth. Further modifications to the original design involved the power supply and fiber optics. Interested readers may obtain these modifications from the authors.

\section{Installation of Mini-rhizotrons}

Mini-rhizotrons were constructed of Pyrex glass (122-cm length, 38-mm o.d., 2-mm wall thickness, Corning Glass Works, VWR Scientific), and cut to a $91-\mathrm{cm}$ length. To allow insertion of the mini-rhizotrons into the soil, holes were excavated with a $3.8-\mathrm{cm}$ diam hand auger and 4.5-cm o.d. soil corer at a 15 degree angle from vertical. Locations were such that the top and bottom of each mini-rhizotron were $10-15 \mathrm{~cm}$ away from and $78 \mathrm{~cm}$ beneath the base of an orchardgrass plant. A $10-\mathrm{cm}$ length of each minirhizotron remaining above the soil surface was sufficient to allow attachment of the root periscope, yet reduced the risks of trampling and breakage by cattle and native ungulates utilizing the research area. During grazing periods, to shield the top and prevent breakage of mini-rhizotrons, rocks or small logs were positioned on the side of the mini-rhizotron facing away from the plant. Rubber stoppers were placed in both ends of each mini-rhizotron to prevent water and foreign material from entering. Stoppers in the lower ends were sealed with duct tape. The $10-\mathrm{cm}$ lengths of each mini-rhizotron above the soil surface were covered with metal cans to prevent sunlight from entering. Roots exposed to light may suberize more rapidly (Hilton and Mason 1971, in Hermann 1977) and their growth may be inhibited (Lake 1987, Levan et al. 1987).

The total number of mini-rhizotrons installed on the research area was $68 ; 24$ were installed beneath orchardgrass plants and 44 were installed beneath conifer seedlings for another portion of the study. Of the 68,32 were located in a 4.45 -ha area grazed by cattle and native ungulates; 36 were located in areas ungrazed by cattle but grazed by native ungulates.

\section{Cost}

Total cost for our root periscope (not including power source) was about $\$ 1,200$ in 1988 (custom-built by Dept. of Agricultural Engineering, Oregon State Univ., Corvallis). Root periscopes can also be purchased from JRD Merrill Specialty Equipment, Logan, Utah, for $\$ 1,000$ (1989 price). Pyrex glass for the mini-rhizotrons was bulk-purchased at a cost of $\$ 152.75 / 11.35 \mathrm{~kg}(\sim \$ 8.50 /$ tube, 1988 price). Cost of the glass cutting was about $\$ 1.10 /$ tube.

\section{Grazing Schedule}

Stocking densities, length of time cattle were present on the grazed area, and utilization (i.e., stubble height) of orchardgrass plants monitored with the in 1988 varied by grazing period and are shown in Table 1.

Table 1. Stocking densities (AU/ha), grazing time (days), stubble heights ( $\bar{x}$ SE, cm) and sample sizes (n) of orchardgrass plants, for grazing periods in 1988.

\begin{tabular}{lcccc}
\hline \hline Month & $\begin{array}{c}\text { Stocking } \\
\text { density }\end{array}$ & $\begin{array}{c}\text { Grazing } \\
\text { time }\end{array}$ & $\begin{array}{c}\text { Stubble } \\
\text { height }\end{array}$ & $\mathrm{n}$ \\
\hline April & $2.7-4.4$ & 8 & $6.9(0.33)$ & 49 \\
May & 4.4 & 5 & $12.1(0.49)$ & 34 \\
June & 4.4 & 3 & $9.6(0.63)$ & 51 \\
& $<4.4$ & 3 & & \\
\hline
\end{tabular}

\section{Root Sampling}

Before installation, the entire length of each mini-rhizotron was marked externally with horizontal, circumferential lines at intervals of $50 \mathrm{~mm}$. A waterproof black pen was used. One-fourth ( 90 degrees) of the circumference of each mini-rhizotron could be viewed by the mirror/fiber optic system at one time. Of the 4 available fields, only 2 were observed down the length of each mini-rhizotron because of time limitations. We chose the 2 fields such that they were side by side and represented the 180 degrees of the mini-rhizotron circumference facing the base of the orchardgrass plant. Fifteen depths (ranging from 1 to $71 \mathrm{~cm}$ in $5-\mathrm{cm}$ increments) were sampled for each of the 2 fields, for a total of 30 subsamples per mini-rhizotron. Root counts were summed for the 30 subsamples, resulting in a relative, total number of roots for a vertical depth of about $0.7 \mathrm{~m}$ for each mini-rhizotron. The method used in counting roots was derived from Tennant (1975). Comparison of root counts between grazed and ungrazed orchardgrass plants was made utilizing an unequal sample size, $t$-test procedure for independent samples at $P=0.05$ (Sokal and Rohlf 1973).

\section{Results and Discussion}

\section{Mini-rhizotron Damage}

Cattle trampled only 2 of the 32 mini-rhizotrons in the cattlegrazed area such that the entire exposed portion was destroyed; an additional 1 was partially damaged. None of the $36 \mathrm{mini}$ rhizotrons in areas grazed only by native ungulates were trampled, despite grazing impacts by these ungulates during the winters of 1987-88 and 1988-89 (unpublished data). These 36 mini-rhizotrons were not protected by rocks or small logs.

\section{Application and Cautions/Limitations}

The root periscope/mini-rhizotron technique allowed an examination of root growth of cattle-grazed vs. ungrazed orchardgrass (Fig. 1). Defoliation during the 3 cattle-grazing periods

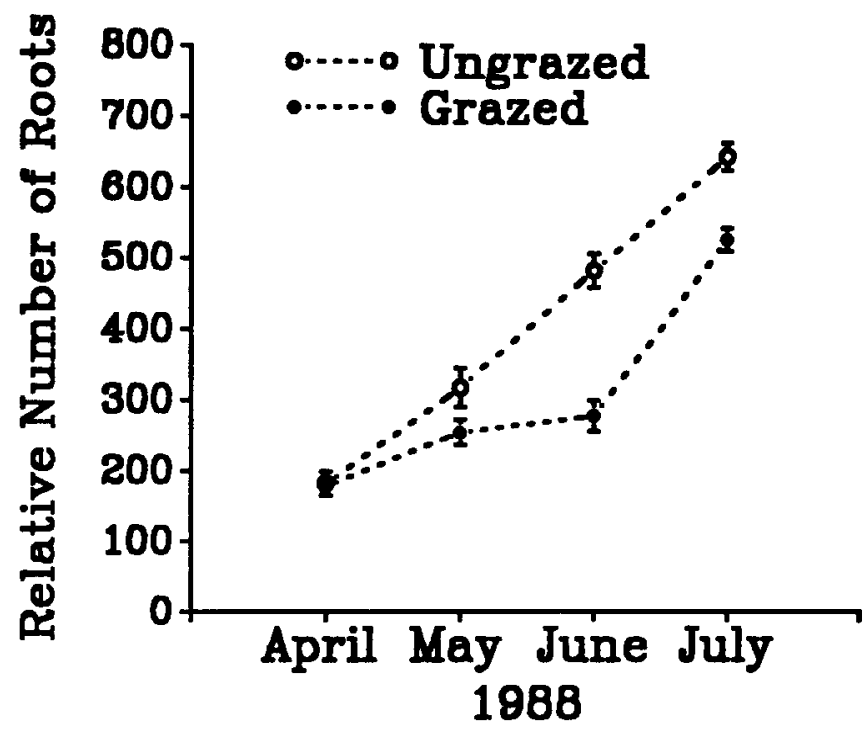

Fig. 1. Relative number of roots $(\bar{x} \pm S E$ ) of grazed $[n=13$ (April); $n=12$ (May-July)] vs. ungrazed ( $=9$ ) orchardgrass, April through July 1988.

(18-26 April, 16-21 May, and 8-1 1, 13-16 June) in 1988 resulted in a reduction in the relative number of roots for grazed, compared to ungrazed, orchardgrass plants. In May ( 18 to 26 days after the end of the first grazing period), the relative number of roots for grazed orchardgrass had begun to decline but was not significantly different $(P=0.06)$ compared to ungrazed orchardgrass. During June 
and July the accumulative, adverse effects of cattle grazing on root growth were apparent, as the relative number of roots for grazed orchardgrass was less $(P<0.001)$ compared to ungrazed orchard grass.

Large variability (experimental error) associated with root sampling has been reported by many researchers (Rowse and Phillips 1974, Sanders and Brown 1978, Upchurch and Ritchie 1983, Taylor 1986, McMichael and Taylor 1987, Upchurch 1987). Coeffcients of variation (C.V.) in this study for the 4 root sampling periods in Figure 1 ranged from 8.8 to $27.7 \%$ for the ungrazed orchard grass, and 10.4 to $26.7 \%$ for the grazed orchardgrass. The C.V. for roots of ungrazed orchardgrass steadily declined from April to July, while the C.V. for roots of grazed orchardgrass generally increased during this time period. This indicates that cattle grazing and concomitant uneven defoliation of plants may be causal in increasing experimental error associated with root counts of grazed orchardgrass plants. A greater sample size (minirhizotrons) for grazed plants vs. ungrazed plants may reduce experimental error and facilitate detection of treatment differences.

Time required to sample each mini-rhizotron increases with: (a) increase in sampling depth; (b) smaller depth increments; and (c) increase in fields at each depth. Böhm et al. (1977) required $40 \mathrm{~min}$ to sample each mini-rhizotron to a $1.8 \mathrm{~m}$ depth at $5-\mathrm{cm}$ intervals; Gregory (1979) required $45 \mathrm{~min}$ to monitor root growth around the entire circumference of each mini-rhizotron to a depth of $0.6 \mathrm{~m}$; Richards (1984) required $20 \mathrm{~min}$ to sample each mini-rhizotron to a $1 \mathrm{~m}$ depth at 5 -cm intervals. A comparable time period (50 $\mathrm{min}$ ) was required in our study to sample each mini-rhizotron. Because root counts were fairly homogeneous among the 2 fields at each depth, we could have substantially reduced the time required to sample each mini-rhizotron and increased our sample size by monitoring root counts for only 1 field at each depth.

Cautions and limitations we propose for mini-rhizotron use on rangelands include:

1. Avoid excitation of grazing animals.

The presence and grazing activity of livestock and/or native ungulates greatly increases the probability of trampling and breakage of mini-rhizotrons. The greater the length of minirhizotron remaining above the soil surface, the greater the probability of trampling and breakage. The relatively short, 10-cm length of mini-rhizotron exposed above the soil surface, with the use of metal cans and natural debris as shields, minimized trampling and breakage. Spooking or disturbing livestock and/or native ungulates can trigger rapid movement within areas containing mini-rhizotrons and should be prevented.

2. Achieve good bulk soil/mini-rhizotron contact.

Achieving this in our study was difficult in soils with coarse fragments or rocks and would probably be difficult in soils with a caliche layer. Soils with these characteristics are commonly found on rangelands, therefore the ubiquitous use of the root periscope/mini-rhizotron technique on some sites may not be feasible.

3. Prevent formation of condensation on exterior of minirhizotrons.

During winter months condensation occasionally formed on the subterranean, exterior surface of the mini-rhizotrons, preventing root observation. Lower ambient air temperatures at night compared to the soil may have created a temperature gradient at the bulk soil/mini-rhizotron interface, resulting in condensation (Richards, personal communication). To prevent formation of condensation, pipe insulation was wrapped around exposed ends of the mini-rhizotrons. From subsequent measurements we found pipe insulation aided in remedying this problem.
4. Monitoring root growth of species mixtures simultaneously.

Roots of species mixtures may be distinguishable from each other using the root periscope/mini-rhizotron technique (Richards 1984). Roots of conifer seedlings and orchardgrass in our study were not distinguishable from each other with absolute certainty because: (a) the fine roots observed were too small to allow detection of differences (color, e.g.); and (b) once suberized, roots of conifer seedlings were usually distinguishable from orchardgrass, but during the period of active root initiation/elongation they were not distinguishable from orchardgrass. Additional cautions and limitations on the use of this technique can be found in papers by Böhm et al. (1977), Böhm (1979), Gregory (1979), Upchurch and Ritchie (1983), and McMichael and Taylor (1987).

\section{Literature Cited}

Bates, G.H. 1937. A device for the observation of root growth in the soil. Nature (London) 139:966-967.

Böhm, W. 1979. Methods of studying root systems. Springer-Verlag, Inc., New York.

Böhm, W., H. Maduakor, and H.M. Taylor. 1977. Comparison of five methods for characterizing soybean rooting density and development. Agron. J. 69:415-419.

Brown, D.A., and D.R. Upchurch. 1987. Minirhizotrons: a summary of methods and instruments in current use, p. 15-30. In: H.M. Taylor(ed.), Minirhizotron observation tubes: methods and applications for measuring rhizosphere dynamics. ASA Special Pub. 50, Amer. Soc. Agron., Crop Sci. Soc. Amer., and Soil Sci. Soc. Amer., Madison, Wis.

Gregory, P.J. 1979. A periscope method for observing root growth and distribution in field soil. J. Exp. Bot. 30:205-214.

Hermann, R.K. 1977. Growth and production of tree roots: a review, p. 7-28. In: J.K. Marshall (ed.), The below-ground ecosystem: a synthesis of plant associated processes. Range Sci. Dept., Science Ser. 26, Colorado State Univ., Fort Collins.

Lake, J.V. 1987. Prologue: interactions in the physical environment of plant roots, p. ix-xiii. In: P.J. Gregory, J.V. Lake, and D.A. Rose (eds.), Root development and function. Soc. for Exp. Biol. Sem. Ser. 30. Cambridge Univ. Press, Cambridge.

Levan, M.A., J.W. Ycas, and J.W. Hummel. 1987. Light leak effects on near-surface soybean rooting observed with minirhizotrons, p. 89-98. In: H.M. Taylor (ed.), Minirhizotron observation tubes: methods and applications for measuring rhizosphere dynamics. ASA Special Pub. 50, Amer. Soc. Agron., Crop Sci. Soc. Amer., and Soil Sci. Soc. Amer., Madison, Wis.

McMichael, B.L., and H.M. Taylor. 1987. Applications and limitations of rhizotrons and minirhizotrons, p. 1-13. In: H.M. Taylor (ed.), Minirhizotron observation tubes: methods and applications for measuring rhizosphere dynamics. ASA Special Pub. 50, Amer. Soc. Agron., Crop Sci. Soc. Amer., and Soil Sci. Soc. Amer., Madison, Wis.

Richards, J.H. 1984. Root growth response to defoliation in two Agropyron bunchgrasses: field observations with an improved root periscope. Oecologia (Berlin) 64:21-25.

Rowse, H.R., and D.A. Phillips. 1974. An instrument for estimating the total length of root in a sample. J. Appl. Ecol. 11:309-314.

Sanders, J.L., and D.A. Brown. 1978. A new fiber optic technique for measuring root growth of soybeans under field conditions. Agron. J. 70:1073-1076.

Sokal, R.R., and F.J. Rohlf. 1973. Introduction to biostatistics. W.H. Freeman and Co., San Francisco.

Taylor, H.M. 1986. Methods of studying root systems in the field. HortSci. 21:952-956.

Tennant, D. 1975. A test of a modified line intersect method of estimating root length. J. Ecol. 63:995-1001.

Upchurch, D.R. 1987. Conversion of minirhizotron-root intersections to root length density, p. 51-65. In: H.M. Taylor (ed.), Minirhizotron observation tubes: methods and applications for measuring rhizosphere dynamics. ASA Special Pub. 50, Amer. Soc. Agron., Crop Sci. Soc. Amer., and Soil Sci. Soc. Amer., Madison, Wis.

Upchurch, D.R., and J.T. Ritchie. 1983. Root observations using a video recording system in mini-rhizotrons. Agron. J. 75:1009-1015.

Vos, J., and J. Groenwold. 1983. Estimation of root densities by observation tubes and endoscope. Plant Soil. 74:295-300.

Waddington, J. 1971. Observation of plant roots in situ. Can. J. Bot. 49:1850-1852. 